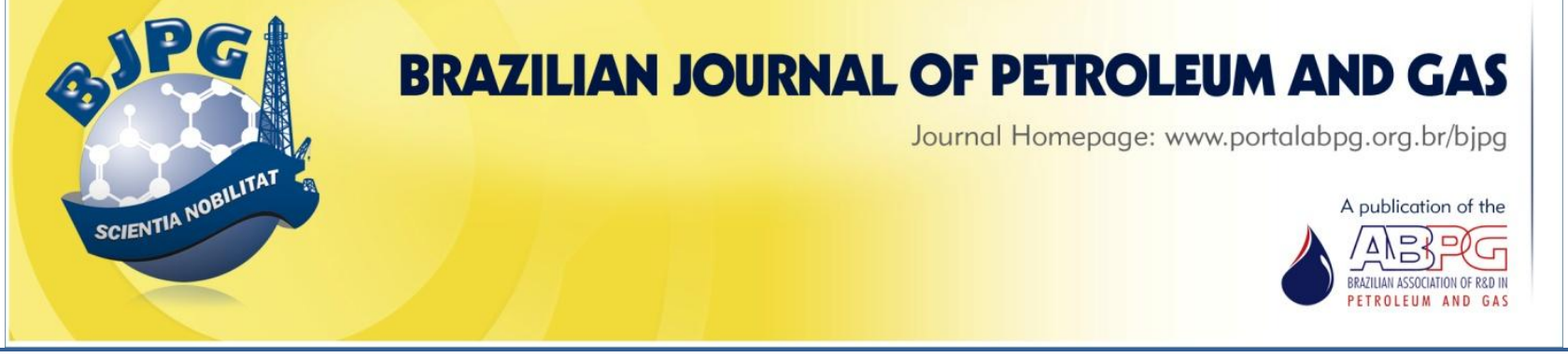

\title{
THERMODYNAMIC STABILITY OF WATER-IN-OIL EMULSIONS
}

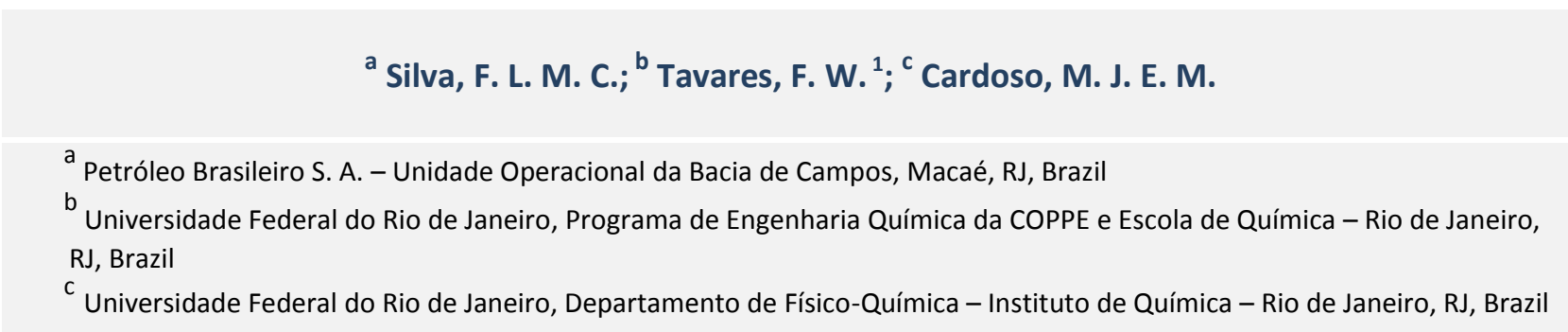

It is well known that colloids can show phase transitions similar to the ones observed in molecular systems. Colloid-diluted and colloid-concentrated phases can coexist in thermodynamic equilibrium at certain conditions. In a previous work, the authors of this research have used this concept to study petroleum emulsions stability, applying thermodynamic perturbation theories to calculate a phase diagram of water-in-oil emulsions under the influence of an electric field. In this work, it was used a similar thermodynamic formalism coupled with the Lifshitz theory to perform a qualitative analysis of the influence of some variables on emulsion stability. Among the variables studied were temperature, applied electric field, and salt concentration. This research found that droplet diameter is a key parameter in studying thermodynamic stability. Variables like temperature and oil composition can have an opposite effect on thermodynamic and kinetic stability. The application of an electric field can destabilize thermodynamically the emulsion. It can also induce meta-stable transitions, which are important for the calculation of droplet coagulation rate. The results presented in this work are in accordance with trends of experimental and industrial observations, and seek to promote a better understanding of water-in-oil emulsion stability.

\section{KEYWORDS}

emulsion stability; phase transitions; dewatering; perturbation theory; Lifshitz theory

\footnotetext{
${ }^{1}$ To whom all correspondence should be addressed.

Address: Programa de Engenharia Química da COPPE e Escola de Química, Universidade Federal do Rio de Janeiro, Av.

Brigadeiro Tropowski, Centro de Tecnologia, Bloco E, Ilha do Fundão, Rio de Janeiro, RJ - Brazil

Telephone / Fax: +55 21 2562-7567 / +55 21 2562-7650 | E-mail: tavares@eq.ufri.br

doi:10.5419/bjpg2013-0001
} 


\section{INTRODUCTION}

In petroleum-production operations, crude oil is normally produced in the form of brine and oil moisture. The shear stress in pipes and valves can disperse brine droplets into the oil medium, and the natural occurrence of some petroleum compounds, such as asphaltenes, resins and fine solids, trends to adsorb at the water-oil interface, forming a mechanically resistant film which stabilizes the brine-in-oil emulsion (Kokal, 2005; Sjöblom et al., 2003; Chen et al., 1994; Sullivan and Kilpatrick, 2002).

This emulsion is much more viscous and voluminous than crude oil. Besides, the coproduced brine does not have any economic value on its own, but it can cause several problems at both downstream and upstream operations which include equipment over sizing, high energy consumption, corrosion, and scaling. For these reasons, the crude oil must be dewatered. The process of dewatering crude oil often involves water-in-oil emulsion breaking. Therefore, emulsion stability is a property of great importance to the petroleum industry.

The stability of water-in-crude oil emulsions depend on a number of factors. Among these variables are the heavy materials of crude oils adsorbed at the water-oil interface (asphaltenes, resins, fine solids, and others), temperature, droplet size and droplet size distribution, $\mathrm{pH}$, along with oil and brine composition (Kokal, 2005). In offshore oilfields, crude oil dewatering is a key process at topside production facilities. Compact and efficient processes are required. The oil industries usually apply thermal, mechanical, electric, or chemical methods to break the waterin-oil emulsion. From an energetic point of view, the electric method is the most efficient (Sjöblom et al., 2003). The use of the electric method consists, basically, in applying a high electric field (1 to $10 \mathrm{kV} / \mathrm{cm}$ ) over the emulsion. This process induces dipole interactions between water droplets, aiding coagulation and coalescence processes (Chen et al., 1994).

Emulsion stability usually is treated by the petroleum industry as a kinetic problem (Kokal, 2005). Despite this tradition, many works have pointed out that colloidal systems are subjected to phase transitions, like molecular and ionic systems.
During these transitions, under some conditions, colloid-diluted and colloid-concentrated phases can coexist in thermodynamic equilibrium (Gast et al., 1983; Vincent et al., 1986, 1988; Fillery-Travis et al., 1993). Using the thermodynamic approach, this research aims to obtain a better understanding of the emulsion- breaking process, which involves the knowledge of both kinetic and thermodynamic aspects.

The nature of the effective interaction potential between colloidal particles determines phase diagram characteristics. When the attractive part of the interaction potential is short ranged enough, metastable transitions can occur (Tavares and Prausnitz, 2004). Therefore, for a better understanding of the phase-transition mechanism in emulsions and colloidal systems, it is useful to describe the entire phase diagram. This description includes stable and meta-stable transitions, which may be relevant due to their influence over phasetransition rates (Anderson and Lekkerkerker, 2002).

According to the McMillan-Mayer formalism (McMillan and Mayer, 1945), colloidal systems can be described as a one-component system of particles dispersed in continuum media. The presence of all solvent species is computed in the mean force field of the particle-particle interaction. Based on this consideration, many authors are using, successfully, molecular theories to describe phase transitions in colloidal systems (Gast et al., 1983; Fillery-Travis et al., 1993; Tavares and Prausnitz, 2004). Tavares and Prausnitz (2004) showed that the Barker-Henderson perturbation theory coupled with van der Waals theory for solids consists in a useful way to calculate colloidalphase transitions.

In a previous work, Silva et al. (2008) introduced these thermodynamic concepts to describe petroleum-emulsion stability. The authors considered the thermodynamic aspects involved in emulsion breaking when applying the electric field. Afterwards, Rayat and Feyzi $(2011 ; 2012)$ used this approach to introduce an alternative effective interaction potential between colloidal particles to estimate the electric field required to break waterin-oil emulsions.

In this work, the authors combine the same formalism adopted by Silva et al. (2008) with the Lifshitiz theory (Israelachvili, 1995; Bowen and 
Jenner, 1995). The goal of this work is to perform a qualitative analysis of the influence of some operational variables such as droplet diameter, temperature, electrolyte concentration in aqueous phase, and continuous phase composition over emulsions' thermodynamic stability. The results obtained in this work follow and explain the trends observed in plants and experiments, indicating the importance of the thermodynamic phase equilibrium approach to describe the stability of petroleum emulsions.

\section{THEORY}

Starting from the knowledge of effective interaction potential between colloidal particles, it is possible to apply molecular theories to calculate thermodynamic properties of the colloidal systems. In the case of a water-in-crude oil emulsions, colloidal particles are water droplets surrounded by a mechanical resistant film composed by asphaltenes and other substances, such as resins. When this emulsion is submitted to an external electric field, the effective droplet-droplet potential can be described by the following equation:

$u(r)=u_{S}(r)+u_{D}(r)+u_{\mu}(r)$

Where $r$ is the center-to-center distance between two droplets, $u_{\mathrm{S}}$ is the steric repulsive energy due to the presence of an asphaltenic film, $u_{\mathrm{D}}$ is the dispersion energy, and $u_{\mu}$ is the dipole interaction energy, which is proportional to the applied external electric field.

In Eq. (1), the steric repulsive and the dispersion potentials were calculated by the Wu et al. (1999) and Hamaker (1937) equations, respectively. The dipole interaction energy was calculated by a modified Keesom equation, which was developed in a previous work (Silva et al., 2008), as represented below:

$$
\begin{aligned}
& u_{S}(r)=\frac{c}{(r-\sigma)^{6}} \\
& u_{D}(r)=-\frac{H}{12}\left[\frac{\sigma^{2}}{r^{2}-\sigma^{2}}+\frac{\sigma^{2}}{r^{2}}+2 \ln \left(\sigma-\frac{\sigma^{2}}{r^{2}}\right)\right]
\end{aligned}
$$

$\frac{u_{\mu}(r)}{k_{B} T}=-\frac{2}{5}\left(\frac{m^{2}}{4 \pi \varepsilon_{0} \varepsilon_{\text {oil }} k_{B} T \sigma^{3}}\right)^{2}\left(\frac{\sigma}{r}\right)^{6} f_{c}$

Where $c$ is a constant related to the thickness of the asphaltenic film, $H$ is the Hamaker constant, $\varepsilon_{0}$ and $\varepsilon_{o i l}$ are the electric vacuum permittivity and the oil dielectric constant, $m$ is the dipole momentum, $T$ is the temperature, $k_{B}$ is the Boltzmann constant, and $f_{c}$ is a correction factor.

The dipole momentum is given by the product between the applied electric field, the polarizability of water, and water sin oil phase $(m=E \alpha)$, which can be calculated by the following equation (Israelachvili, 1995):

$\alpha=\frac{1}{2} \pi \varepsilon_{0} \varepsilon_{\text {oil }} \sigma^{3}\left(\frac{\varepsilon_{\text {water }}-\varepsilon_{\text {oil }}}{\varepsilon_{\text {water }}+2 \varepsilon_{\text {oil }}}\right)$

The Hamaker constant can be calculated according to the Lifshitz theory (Israelachvili, 1995; Bowen and Jenner, 1995) as:

$H=\frac{3}{4} k_{B} T\left(\frac{\varepsilon_{\text {water }}-\varepsilon_{\text {oil }}}{\varepsilon_{\text {water }}+\varepsilon_{\text {oil }}}\right)^{2}+\frac{3 h v_{e}}{16 \sqrt{2}} \frac{\left(n_{\text {water }}^{2}-n_{\text {oil }}^{2}\right)^{2}}{\left(n_{\text {water }}^{2}+n_{\text {oil }}^{2}\right)^{3 / 2}}$

Where $\varepsilon_{\text {water }}, \varepsilon_{\text {oil }}, n_{\text {water }}$ and $n_{\text {oil }}$ are respectively the dielectric constants and refractive index of aqueous and oily phases, $h$ is the Planck constant, and $v_{e}$ is the main electronic absorption frequency in the ultra-violet (UV), typically around $3 \times 10^{15} \mathrm{~s}^{-1}$.

Equations (5) and (6) show that, by knowing the influence of any variable on dielectric constant and refractive indices of aqueous and oily phases, it is possible to calculate the Hamaker constant and droplet polarizabilty as a function of this variable. Results from these equations together with geometric parameters (droplet diameter and asphaltenic film thickness) allow us to define an effective droplet-droplet interaction potential. From this information, it is possible to calculate the Helmholtz free energy applying the perturbation theory:

$\frac{A}{N k_{B} T}=\frac{A^{r e f}}{N k_{B} T}+\frac{12 \phi}{T} \int_{\sigma}^{\infty} u(r) g^{r e f}(\phi, r) r^{2} d r$

Where $A$ is the Helmholtz free energy, $N$ is the number of droplets, $\phi$ is the water volume fraction, and $g$ is the radial distribution function. The superscript ref indicates de reference system, 


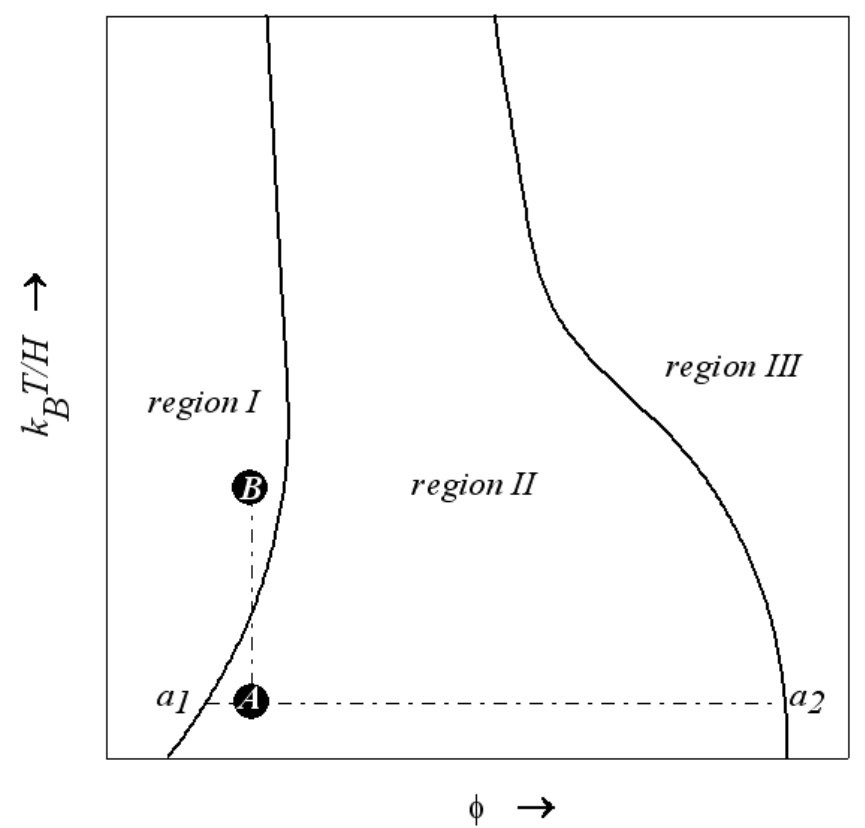

Figure 1. Typical phase diagram for a water-in-oil emulsion without any external field represented as a water volume fraction versus non-dimensional temperature.

which is an arbitrary system whose properties must be well-known. In this work, the authors adopted the hard sphere model as the reference system, using the Carnahan-Staring equation of state (Carnahan and Starling, 1969) for the waterdiluted phase (referred to as "fluid phase"). The model proposed by Velasco et al. (1998) was used for the water-concentrated (referred to as "solid phase"). In order to determine the perturbation term, the Chang and Sandler (1994) equation was employed to calculate the radial distribution function of the fluid phase, and the integral in Eq. (7) was calculated numerically. For the radial distribution function of the solid phase, it was used a simplified van der Waals theory proposed by Daanon et al. (1994).

Classical thermodynamic relations were used to obtain other properties from Eq. (7):

$Z=\phi\left[\frac{\partial\left(A / N k_{B} T\right)}{\partial \phi}\right]$

$\frac{\mu}{k_{B} T}=\frac{A}{N k_{B} T}+Z$

Where $Z$ is the compressibility factor and $\mu$ is the chemical potential.
When two phases are at equilibrium conditions, the pressure and chemical potential of both phases must be equal. Using this premise, at a fixed value of temperature and applied electric field, the water volume fraction of equilibrium phases were calculated by solving the following set of equations:

$\left\{\begin{array}{l}Z^{I} \phi^{I}=Z^{I I} \phi^{I I} \\ \mu^{I}=\mu^{I I}\end{array}\right.$

Where the superscripts I and II refer to the two different phases. The solution of Eq. (10) at different values of temperature or applied electric field leads to the typical phase diagrams are shown in Figures 1 and 2.

Figure 1 shows a typical phase diagram of a water-in-oil emulsion without any external field (in other words, $u_{\mu}(r)=0$ ) represented as water volume fraction $\phi$ versus dimensionless temperature $k_{B} T / H$. In this phase diagram, it is possible to identify three distinct regions: region $I$, where the droplets compose a diluted phase and the emulsion is thermodynamically stable; region $I I$, also known as envelope phase, where dropletdiluted and droplet-concentrated phases are in thermodynamic equilibrium; and region III, where the droplets are arranged in a concentrated and 


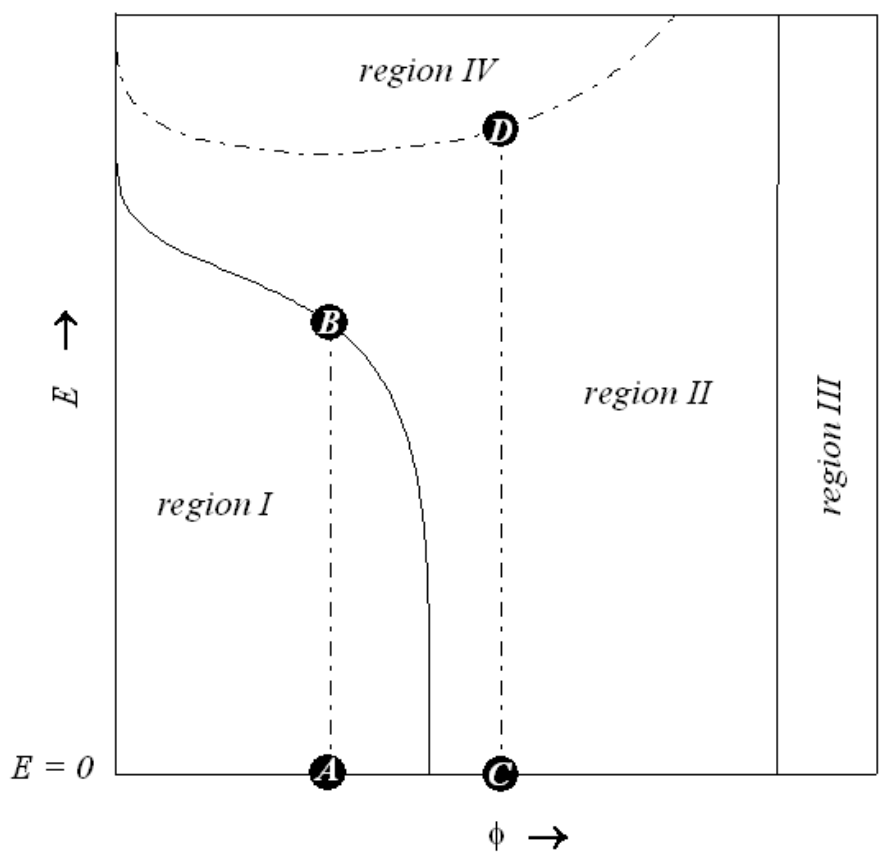

Figure 2. Typical phase diagram for a water-in-oil emulsion as a water volume fraction versus applied electrical field.

structured phase - the phase where the droplet coagulation should occur. An emulsion located at point $A$ should be unstable, because a system composed by two phases, here $a_{1}$ and $a_{2}$, is more stable. An increase in $k_{B} T / H$ can lead the emulsion to the point $B$ (out of the phase envelop), where the emulsion is thermodynamically stable.

Figure 2 shows a typical diagram of a water-inoil emulsion represented as a water volume fraction against applied electric field at a fixed temperature. In this case, besides regions $I$, II, and III identified in Figure 1 , there is a region IV, which comprehends the metastable transition phase envelop, where two non-structured phases (one diluted and other concentrated) are in metastable equilibrium. This region is important because it can accelerate the droplet nucleation rate (Anderson and Lekkerkerker, 2002). By this phase diagram, a stable emulsion located in point $A$ can be destabilized by applying an electric field, which leads it to point $B$. On the other hand, the droplet nucleation rate of an unstable emulsion located at point $C$ can be accelerated by applying an electric field, which leads it to point $D$, at the metastable transition phase envelop line.

\section{RESULTS AND DISCUSSION}

In this work, it was evaluated the effect of temperature and electrolyte concentration of aqueous phase using the Hamaker constant, polarizabilities, dielectric constants, and refractive indexes. Because these variables are related directly with the colloid-colloid interaction potentials, it is possible to evaluate the non-linear effect of temperature and electrolyte concentration on the phase diagram.

An empirical equation published by Lide (2000), was used to calculate the temperature dependence of dielectric constant. This equation can be applied to several substances at a wide range of temperatures. For the refractive index of hydrocarbons, this work used the experimental data at $20^{\circ} \mathrm{C}$, published by Ward and Kurtz (1938), and the temperature correction proposed by Lipkin and Kurtz (1941). For the calculation of the refractive index of pure water as a function of temperature, one used the experimental data available from literature (Lide, 2000) to fit the following equation: 


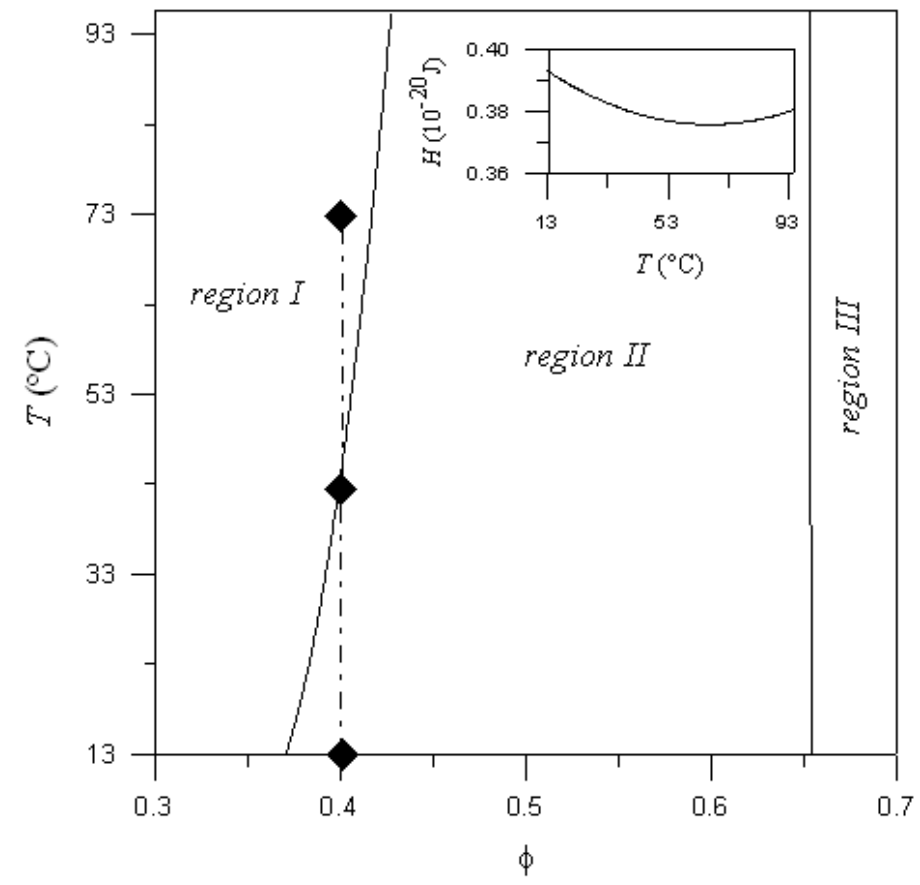

Figure 3. Phase diagram of a water-in-n-octane emulsion with droplet diameter $\sigma$ equal to $1 \mu \mathrm{m}$ and an asphaltenic film thickness $\delta$ equal to $12 \mathrm{~nm}$. The smaller figure at the higher right corner shows the effect of temperature on the Hamaker constant.

$n_{\text {water }}=1.33455-4.50249 \times 10^{-5} \tau-$

$-1.16002 \times 10^{-6} \tau^{2}$

Where $\tau$ is the temperature in ${ }^{\circ} \mathrm{C}$.

In order to take into account the effect of electrolyte concentration on aqueous phase properties, this work used the equation proposed by Buchner et al. (1999) for dielectric constant of electrolyte solutions, and the experimental data of refractive index from literature (Leyendekkers and Hunter, 1977) to fit the following equation:

$$
n_{\text {water }}=1.331+0.0098 C_{m}-0.002 C_{m}^{2}
$$

Where $\mathrm{Cm}$ is the electrolyte concentration in $\mathrm{mol} / \mathrm{L}$. It is considered here that all electrolytes are in aqueous phase, therefore, maintaining the bulk properties of the oil phase.

Figure 3 shows the phase diagram of a water-inn-octane without external field. The curve represents the function between water volume fraction versus temperature. In this case, it was considered a droplet diameter equal to $1 \mu \mathrm{m}$ and an asphaltenic film with thickness equal to $12 \mathrm{~nm}$. An emulsion with water volume fraction of 0.4 described by this phase diagram should be unstable at $13^{\circ} \mathrm{C}$. The equilibrium line should be trigged when the temperature increases, until $43^{\circ} \mathrm{C}$. At $73^{\circ} \mathrm{C}$, the emulsion is considered thermodynamically stable. This result is quite interesting because of its implication on the wellestablished temperature effect on emulsion kinetic stability.

In order to explain kinetic effects on emulsion stability, two phenomena are commonly used: velocity droplet sedimentation, which is commonly described by petroleum industry by Stokes law for terminal velocity; and the droplet coagulation rate, described by Smoluchowski law.

The droplet terminal velocity is described by the following equation (Abdel-Aal et al., 2003):

$v_{t}=\frac{\left(D_{w}-D_{o}\right) \sigma^{2}}{18 \eta}$

Where $D_{w}$ and $D_{o}$ are the aqueous and oily phase mass densities, $\sigma$ is the droplet diameter, and $\eta$ is the oily phase viscosity. 


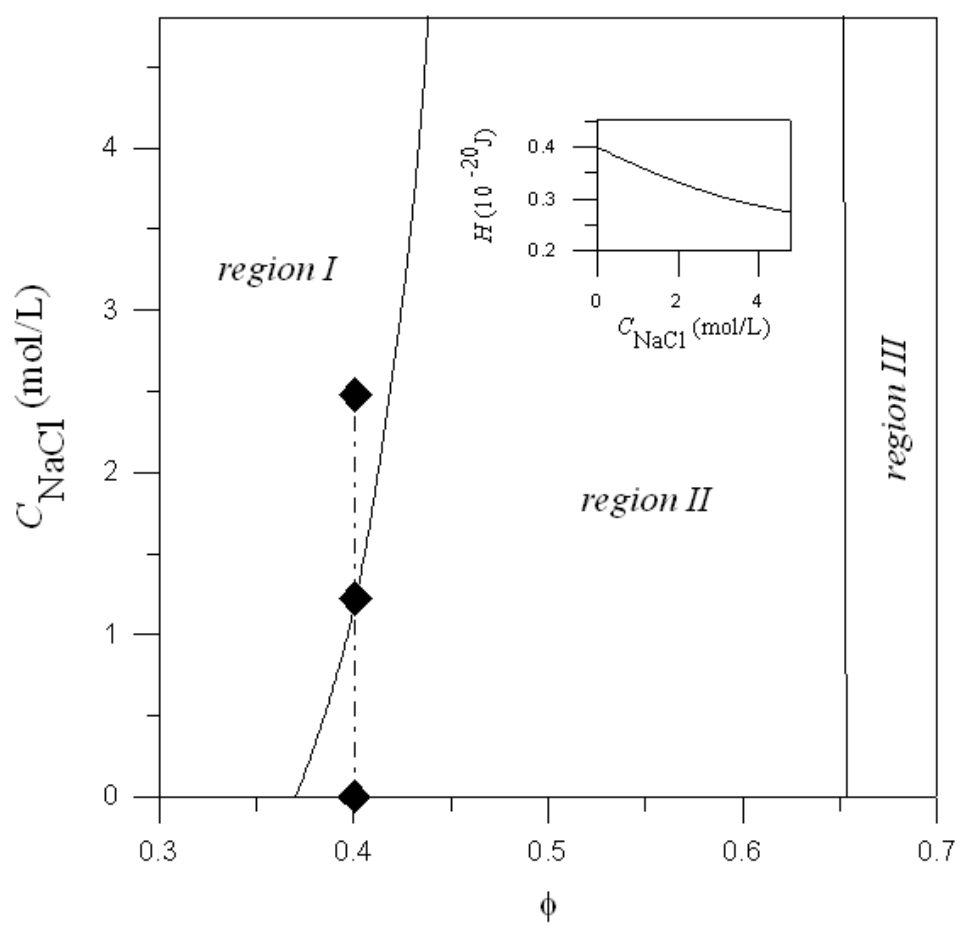

Figure 4. Phase diagram of a brine-in-n-octane emulsion at $20^{\circ} \mathrm{C}$ with droplet diameter $\sigma$ equal to $1 \mu \mathrm{m}$ and an asphaltenic film thickness $\delta$ equal to $12 \mathrm{~nm}$. The smaller figure at the higher right corner shows the effect of electrolyte $(\mathrm{NaCl})$ concentration over Hamaker constant.

The rate calculated by Smoluchowski law for droplet coagulation is defined by the following equation (Adamson and Gast, 1997):

$$
\frac{d \rho}{d t}=-k \rho^{2}
$$

Where the rate constant $k$ is given by:

$$
k=\frac{8 k_{B} T}{3 \eta} \exp \left[-\frac{E}{k_{B} T}\right]
$$

In Eq. (14), $\rho$ is the droplet number density, $t$ is the time, and $E$ is the energy barrier to coagulation.

Therefore, Equations (13) and (14) show that, at higher temperatures, terminal velocity and coagulation rates are higher, and, consequently, the emulsion instability is enhanced. Using the thermodynamic approach, emulsions are more stable at high temperatures. On a different note, through the kinetic approach, emulsions are less stable at high temperatures.

Figure 4 shows the phase diagram of a water-in$\mathrm{n}$-octane emulsion at $20^{\circ} \mathrm{C}$ as a water volume fraction versus aqueous-phase electrolyte concentration curve. One can see that increasing the electrolyte concentration, it reduces the Hamaker constant. This change can direct the emulsion from the inside to the outside of the phase envelop, where the system is thermodynamically stable. For the sake of being concise, the details of phase diagram calculations are shown elsewhere (Silva et al., 2008).

Works addressing the effects of salt addition to water in oil emulsions can be found in literature. Kent and Saunders (2001) proposed that water-inoil emulsions are stabilized by salt addition due to changes in surfactant adsorption kinetics. Aronson and Petko (1993) concluded that interactions between surfactants polar groups and ions dissolved in water contribute to emulsion stabilization. Our results show that, beside these factors, another two conditions should contribute to the emulsion stabilization at higher salt concentrations. The first one is the reduction on the Hamaker constant, and consequently a diminution in the attractive force between droplets. This kinetic decline should decrease the number of effective shocks between droplets. The 


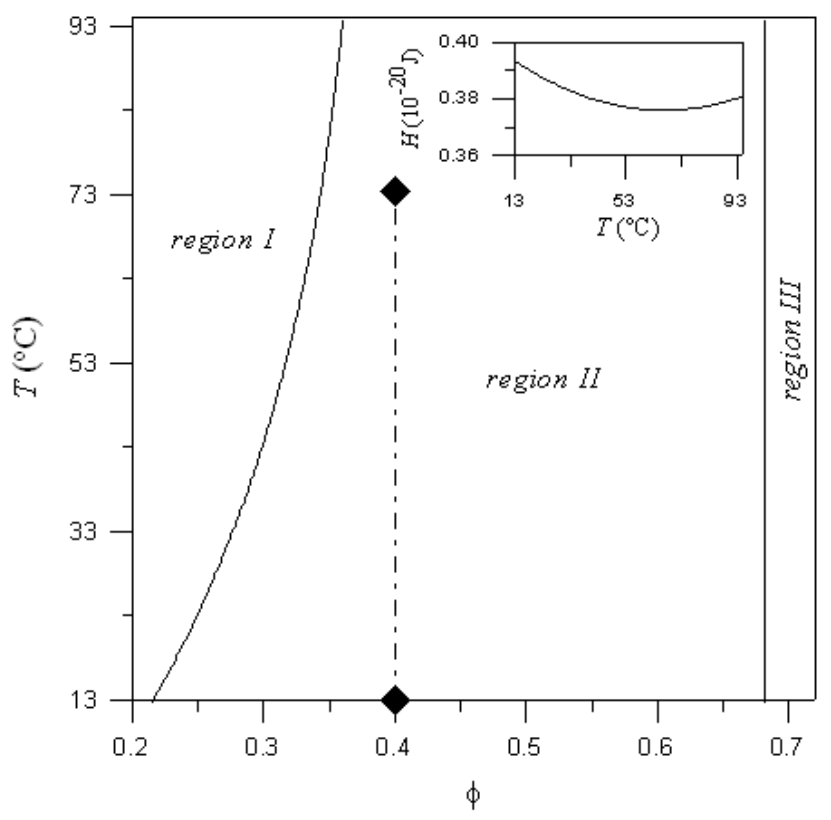

Figure 5. Phase diagram of a water-in-n-octane emulsion with droplet diameter equal $\sigma$ to $1.5 \mu m$ and an asphaltenic film thickness $\delta$ equal to $12 \mathrm{~nm}$. The smaller figure at the higher right corner shows the effect of temperature over Hamaker constant.

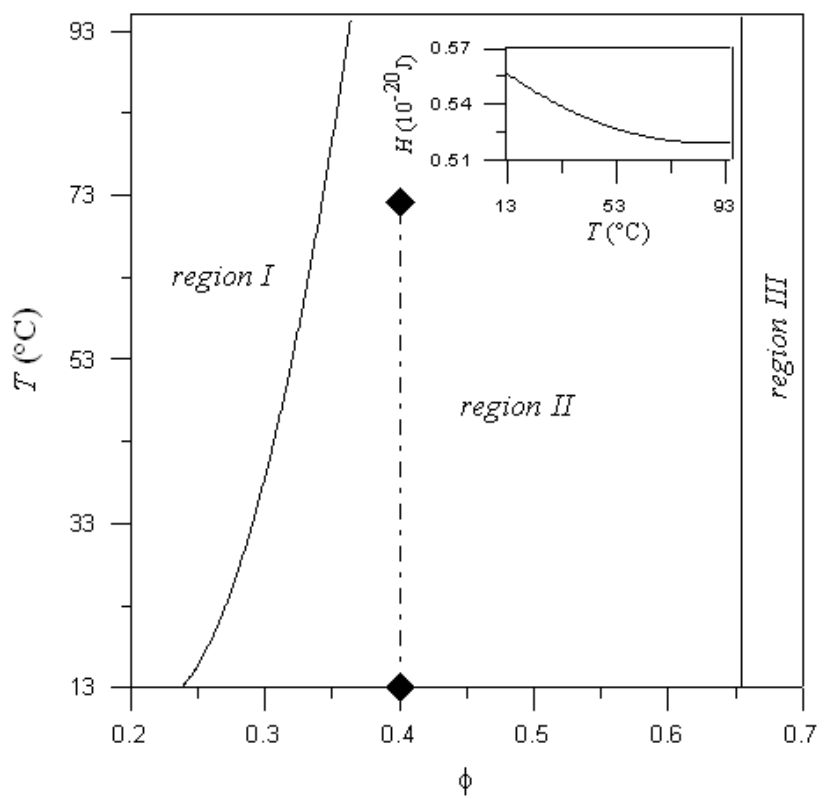

Figure 6. Phase diagram of a water-in-n-hexadecane emulsion with droplet diameter $\sigma$ equal to $1 \mu \mathrm{m}$ and an asphaltenic film thickness $\delta$ equal to $12 \mathrm{~nm}$. The smaller figure at the higher right corner shows the effect of temperature over Hamaker constant.

second factor is the thermodynamic stabilization, which occurs when the salt addition is high enough to take the emulsion out of the phase envelope.

Figure 5 shows the phase diagram of a water-inn-octane emulsion without external field. In this case, it was considered a droplet diameter equal to $1.5 \mu \mathrm{m}$ and an asphaltenic film of thickness equal to $12 \mathrm{~nm}$. Through the comparison between Figures 3 and 5 , one can observe that the emulsions are much more stable for smaller droplets. 
Table 1. Hamaker constant for several water-in-crude oil emulsions.

\begin{tabular}{|c|c|c|c|c|}
\hline \multirow{2}{*}{$\begin{array}{l}\text { Crude Oil } \\
\text { Type }\end{array}$} & \multicolumn{3}{|c|}{$\begin{array}{c}\text { Crude Oil Properties } \\
\text { (Goual and Firoozabadi, 2002) }\end{array}$} & \multirow{2}{*}{$\begin{array}{l}\text { Hamaker constant } \\
\text { for water-in-oil } \\
\text { emulsion }\left(10^{-20} \mathrm{~J}\right)\end{array}$} \\
\hline & Gravity (API) & $\begin{array}{c}\text { Dielectric } \\
\text { constant at } 20 \circ \mathrm{C}\end{array}$ & $\begin{array}{c}\text { Refractive } \\
\text { index at } 20 \circ \mathrm{C}\end{array}$ & \\
\hline Crude I & 9 & 2.6 & 1.527 & 1.27 \\
\hline Crude II & 10 & 2.5 & 1.522 & 1.22 \\
\hline Crude III & 33 & 2.2 & 1.487 & 0.92 \\
\hline Crude IV & 37 & 2.3 & 1.497 & 1.00 \\
\hline Crude V & 35 & 2.4 & 1.496 & 0.99 \\
\hline Crude VI & 32 & 2.4 & 1.498 & 1.00 \\
\hline Crude VII & 34 & 2.4 & 1.496 & 0.99 \\
\hline Crude VIII & 56 & 2.1 & 1.472 & 0.80 \\
\hline
\end{tabular}

Figure 6 shows the phase diagram of a water-inhexadecane emulsion, with droplet diameter equal to $1 \mu \mathrm{m}$ and an asphaltenic film thickness equal to $12 \mathrm{~nm}$. In this case, the higher Hamaker constant produced a more unstable emulsion when compared with the -water-in-octane emulsion depicted in Figure 3. In fact, the continuous media effect over the Hamaker constant can also lead to situations where kinetic and thermodynamic stability are in opposite directions. Table 1 shows the Hamaker constant, calculated for different petroleum emulsions. Despite the inexistence of a general rule, one can see that heavier oil emulsions usually shows higher Hamaker constants, which is reflected in more unstable emulsions. If one considers that heavy oils usually are more viscous, it should be expected that heavy oil emulsions should be more stable from a kinetic point of view. These characteristics imply that kinetic and thermodynamics show opposite effects on emulsion stability.

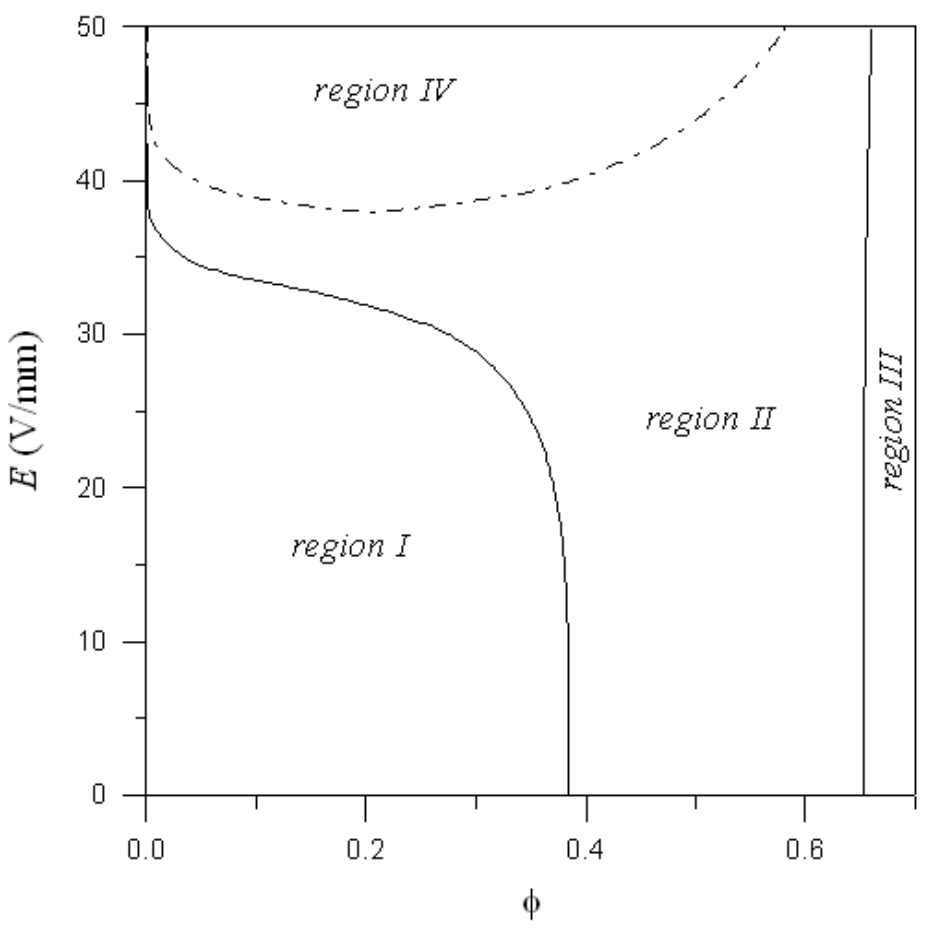

Figure 7. Phase diagram of a water-in-n-octane emulsion at $25^{\circ} \mathrm{C}$ with droplet diameter $\sigma$ equal to $1 \mu \mathrm{m}$ and an asphaltenic film thickness $\delta$ equal to $12 \mathrm{~nm}$. 


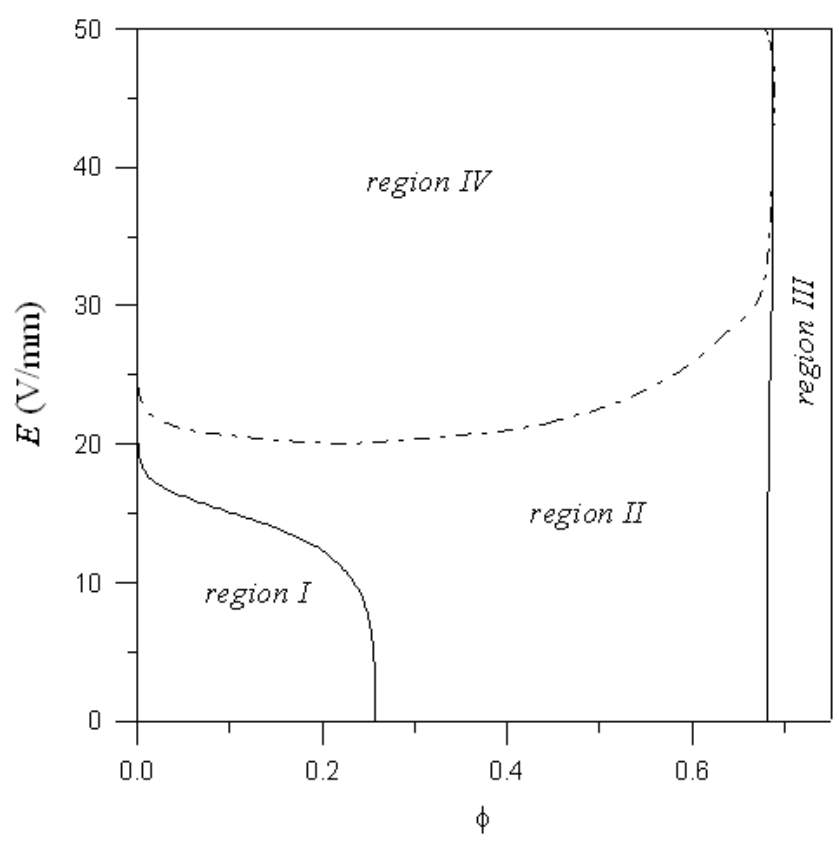

Figure 8. Phase diagram of a water-in-n-octane emulsion at $25^{\circ} \mathrm{C}$ with droplet diameter $\sigma$ equal to $1.5 \mu \mathrm{m}$ and an asphaltenic film thickness $\delta$ equal to $12 \mathrm{~nm}$.

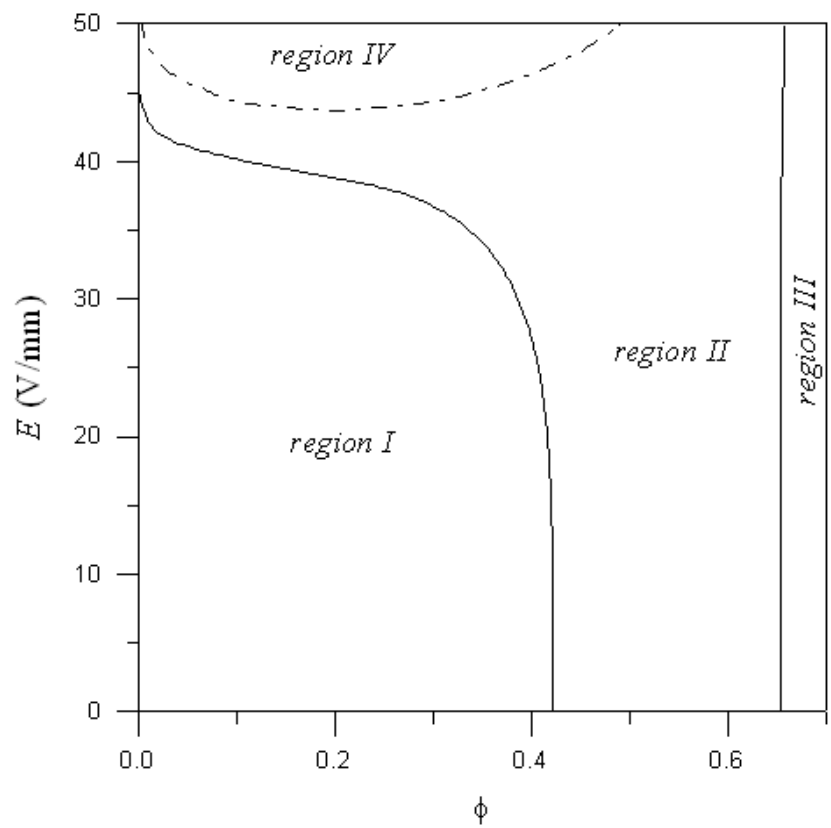

Figure 9. Phase diagram of a water-in-n-octane emulsion at $85^{\circ} \mathrm{C}$ with droplet diameter $\sigma$ equal to $1 \mu \mathrm{m}$ and an asphaltenic film thickness $\delta$ equal to $12 \mathrm{~nm}$.

It is well known that the application of an external electric field over a water-in-oil emulsion polarizes the water droplets and induces dipoledipole interactions among these particles (Kokal, 2005). The additional dipole interaction potential $u_{\mu}$, due to the applied external field, increases the attraction and, at some conditions, can induce phase separation. Figure 7 shows the phase diagram of a water-in-n-octane emulsion at $25^{\circ} \mathrm{C}$ and with a droplet diameter $\sigma=1 \mu \mathrm{m}$. The graphs show the water volume fraction against the applied electric field curve. The dashed line represents the metastable transition, which occurs when the applied electric field is high enough. Because the 
metastable phase may be part of the pathway of droplet nucleation, this non-stable phase contributes to the increase in coagulation rate.

Figure 8 shows the phase diagram of a water-inn-octane emulsion with droplet diameter $\sigma=$ $1.5 \mu \mathrm{m}$. Note that in this case a lower electric field is required for the same phase separation observed in Figure 7, which means that emulsions with larger droplets should be less stable. Figure 9 shows the phase diagram of a water-in-n-octane emulsion with droplet diameter $\sigma=1 \mu \mathrm{m}$ at $85^{\circ} \mathrm{C}$. In this case, the emulsion is more stable than that at $25^{\circ} \mathrm{C}$ showed in Figure 7. This difference in stability shows that a higher electric field is required for the same phase separation. However, when comparing these results with the ones shown in Figure 8, one can see that temperature is not as sensitive as a variable as the droplet diameter is.

\section{CONCLUSIONS}

Following the guidelines presented in a previous work (Silva et al., 2008), this paper calculated phase diagrams for water-in-oil emulsions based on water droplets effective interaction potential. In order to evaluate real systems behavior, properties of some defined hydrocarbons were used to obtain the Hamaker constant and the polarizability of emulsified droplets. The phase diagrams were represented as a result of water volume fraction in function of temperature, aqueous phase electrolyte concentration, or applied electric field curve.

Kinetically, elevated temperatures promote higher emulsion-destabilization rates. However, the present results show that, from a thermodynamic point of view, emulsions are more stable at high temperatures. At low temperatures, emulsions tend to separate into droplet-diluted and droplet-concentrated phases, coexisting in thermodynamic equilibrium.

Droplet diameter is a key parameter in emulsion stability. Besides kinetic reasons, thermodynamicentropic factors also contribute to the high stability of emulsions that contain small droplets. In addition to the mechanisms proposed in literature to describe the water-in-oil emulsion stabilization by electrolyte addition, this research found that the reduction of Hamaker constant and the displacement in the phase diagram can also contribute to this effect.

The chemical nature of the oily phase, as well as the temperature effect, can lead to situations where thermodynamic and kinetic aspects have opposite effects on emulsion stability.

Results show that the application of an external electric field is able to destabilize thermodynamically the emulsion. Moreover, high electric fields can induce metastable transitions, which suggest high coagulation rates. In a general way, the temperature effect is not as significant as droplet diameter is. Nevertheless, special attention should be taken when the system is near the equilibrium line.

Despite the simplifications adopted in this work's calculations (e.g. absence of coalescence, spherical droplets, and monodisperse size distribution), the results obtained here follow the trends of experimental and industrial observations. Results also reveal that thermodynamic aspects are also relevant in the study of emulsion stability. Although the results presented in this research are only qualitative, they can be used to obtain the quantitatively values for emulsions thermodynamic stability, which are useful for process design and plant operations.

\section{ACKNOWLEDGMENTS}

The authors thank the Brazilian agencies Capes (Coordenação de Aperfeiçoamento de Pessoal de Nível Superior) and CNPq (Conselho Nacional de Desenvolvimento Científico e Tecnológico) for the financial support. Foremost, F. C. S. would like to express his sincere gratitude to Petróleo Brasileiro S. A. for backing his activities related to this work.

\section{REFERENCES}

Abdel-Aal, H. K.; Aggour, M.; Fahim, M. A. Petroleum and Gas Field Processing. New York: Markel Dekker Inc., 364p, 2003.

http://dx.doi.org/10.1201/9780203911099

Adamson, A. W.; Gast, A. P. Physical Chemistry of Surfaces. New York: Wiley Interscience Publication, 1997. 
Anderson, V. J.; Lekkerkerker, H. N. W. Insights into phase transition kinetics from colloid science. Nature, v.416, p. $811-815,2002$.

http://dx.doi.org/10.1038/416811a

Aronson, M. P. and Petko, M. F. Highly concentrated water-in-oil emulsion: Influence of electrolyte on their properties and stability. Journal of Colloid and Interface Science, V.159, p. 134-149, 1993. http://dx.doi.org/10.1006/icis.1993.1305

Bowen, W. R.; Jenner, F. The calculations of dispersion forces for engineering applications. Advances in Colloid and Interface Science, v.56, p. 201-243, 1995.

http://dx.doi.org/10.1016/0001-8686(94)00233-3

Buchner, R.; Hefter, G. T.; May, P. M. Dielectric relaxation of aqueous $\mathrm{NaCl}$ solutions. The Journal of Physical Chemistry A, v.103, p. 1-9, 1999. http://dx.doi.org/10.1021/ip982977k

Carnahan, N. F.; Starling, K. E. Equation of state for nonattrating rigid spheres. Journal of Chemical Physics, v.51, p. 635-636, 1969.

http://dx.doi.org/10.1063/1.1672048

Chang, J.; Sandler, S. I. A real function representation for the structure of hard-sphere fluid. Molecular Physics, v.81, p. 735-744, 1994. http://dx.doi.org/10.1080/00268979400100491

Chen, T. Y.; Mohammed, R. A.; Bailey, A. I.; Luckham, P. F.; Taylor, S. E. Dewatering of crude oil emulsions 4. Emulsion resolution by application of an electrical field. Colloids and Surfaces A, v.83, p. 273-284, 1994.

http://dx.doi.org/10.1016/0927-7757(93)02653-V

Daanoun, A.; Tejero, C. F.; Baus, M. van der Waals Theory for Solids. Physical Review E, v.50, p. 2913-2924, 1994.

http://dx.doi.org/10.1103/PhysRevE.50.2913

Fillery-Travis, A. J.; Gunning, P. A.; Hibberd, D. J.; Robins, M. M. Coexistence phases in concentrated polydisperse emulsions flocculated by nonadsorbing polymer. Journal of Colloid and Interface Science, v. 159, p. 187-197, 1993. http://dx.doi.org/10.1006/icis.1993.1311

Gast, A. P.; Hall, C. K.; Russel, W. B. Polymer induced phase separations in nonaqueous colloidal suspensions. Journal of Colloid and Interface Science, v.96, p. 251-267, 1983.

http://dx.doi.org/10.1016/0021-9797(83)90027-9
Goual, L.; Firoozabadi, A. Measuring asphaltenes and resins, and dipole moment in petroleum fluids. AIChE Journal, v. 48, p. 26462663, 2002. http://dx.doi.org/10.1002/aic.690481124

Hamaker, H. C. The London-van der Waals attraction between spherical particles. Physica, v.4, p. 1058-1072, 1937. http://dx.doi.org/10.1016/S00318914(37)80203-7

Israelachvili, J. N. Intermolecular and Surface Forces. London: Academic Press, 1995.

Kent, P.; Saunders, R. The role of added electrolyte in the stabilization of inverse emulsions. Journal of Colloids and Interface Science, v.242, p. 437-442, 2001.

http://dx.doi.org/10.1006/icis.2001.7792

Kokal, S. Crude-oil emulsions: A state-of-art review. SPE Production \& Facilities, v.20, p. 5-13, 2005. http://dx.doi.org/10.2118/77497-PA

Leyendekkers, J. V.; Hunter, R. J. Refractive index of aqueous electrolyte solutions. Extrapolation to other temperatures, pressures, and wavelengths and to multicomponent systems. Journal of Chemical and Engineering Data, v.22, p. 427-431, 1977.

http://dx.doi.org/10.1021/ie60075a019

Lide, D. R. Handbook of Chemistry and Physics. New York: CRC Press, 2000.

Lipkin, M. R.; Kurtz, S. S. Temperature coefficient of density and refractive index for hydrocarbon in liquid state. Industrial and Engineering Chemistry, v.13, p. 291-295, 1941.

McMillan, W. G.; Mayer, J. E. The statistical thermodynamics of multicomponent systems, Journal of Chemical Physics, v.13, p. 276-305, 1945. http://dx.doi.org/10.1063/1.1724036

Rayat, K.; Feyzi, F. Estimation of the electric field strength required for breaking the water-in-oil emulsion: A thermodynamic approach considering droplets deformation and the effect of interfacial tension. Fluid Phase Equilibria, v.316, p. 156-163, 2012. http://dx.doi.org/10.1016/i.fluid.2011.12.001 
Rayat, K.; Feyzi, F. Influence of external electric field on the polarity of water droplets in water-inoil emulsion phase transition. Colloids and Surfaces A: Physicochemical and Engineering Aspects, v.375, p. 61-67, 2011.

http://dx.doi.org/10.1016/i.colsurfa.2010.11.056

Silva, F. L. M. C.; Tavares, F. W.; Cardoso, M. J. E. $M$. Phase transition of water-in-oil emulsions over influence of an external electric field. Colloids and Surfaces A: Physicochemical and Engineering Aspects, v. 326, p. 10-17, 2008.

http://dx.doi.org/10.1016/j.colsurfa.2008.05.004

Sjöblom, J.; Aske, N.; Auflem, I. H.; Brandal, $\varnothing$.; Havre, T. E.; Saether, $\varnothing$.; Westvik, A.; Johnsen, E. E.; Kallevik, H. Our current understanding of water-incrude oil emulsions: Recent characterization techniques and high pressure performance. Advances in Colloids and Interface Science, v.100102, p. 399-473, 2003.

http://dx.doi.org/10.1016/\$0001-8686(02)00066-0

Sullivan, A. P.; Kilpatrick, P. K. The effect of inorganic solid particles on water and crude oil emulsion stability. Industrial and Engineering Chemistry Research, v.41, p. 3389-3404, 2002. http://dx.doi.org/10.1021/ie010927n

Tavares, F. W.; Prausnitz, J. M. Analytic calculations of phase diagrams for solutions containing colloids or globular proteins. Colloid and Polymer Science, v.282, p. 620-632, 2004. http://dx.doi.org/10.1007/s00396-003-0987-x
Velasco, E.; Mederos, L.; Navascués, G. Phase diagram of colloidal systems. Langmuir, v.14, p. 5652-5655, 1998.

http://dx.doi.org/10.1021/la980126y

Vincent, B.; Edwards, J.; Emmett, S.; Jones, A. Depletion flocculation in dispersions of stericallystabilised particles ("soft spheres"). Colloids \& Surfaces, v.18, p. 261-281, 1986.

http://dx.doi.org/10.1016/0166-6622(86)80317-1

Vincet, B.; Edwards, J.; Emmett, S.; Croot, R. Phase separation in dispersions of weaklyinteracting particles in solutions of non-adsorbing polymer. Colloids \& Surfaces, v.31, p. 267-298, 1988. http://dx.doi.org/10.1016/0166-6622(88)80200-2

Ward, A. L.; Kurtz, S. S. Refraction, dispersion, and related properties of pure hydrocarbons. Industrial and Engineering Chemistry, v.10, p. 559576, 1938.

Wu, X.; van de Ven, T. G. M.; Czarnecki, J., Colloidal forces between emulsified water droplets in toluene-diluted bitumen. Colloids and Surfaces A, v.149, p. 577-583, 1999. http://dx.doi.org/10.1016/S0927-7757(98)00312-4 